OPEN ACCESS

Edited by:

Ravi Gupta,

Jamia Hamdard University, India

Reviewed by:

Cristina Sgherri,

University of Pisa, Italy

Salar Farhangi-Abriz,

University of Tabriz, Iran

*Correspondence:

Min Huang

mhuang@hunau.edu.cn

Specialty section:

This article was submitted to Crop and Product Physiology,

a section of the journal

Frontiers in Plant Science

Received: 19 May 2021

Accepted: 15 July 2021

Published: 05 August 2021

Citation:

Huang $M$, Yin X, Chen J and Cao F (2021) Biochar Application Mitigates the Effect of Heat Stress on Rice (Oryza sativa L.) by Regulating the Root-Zone Environment.

Front. Plant Sci. 12:711725. doi: 10.3389/fp/s.2021.711725

\section{Biochar Application Mitigates the Effect of Heat Stress on Rice (Oryza sativa L.) by Regulating the Root- Zone Environment}

\author{
Min Huang*, Xiaohong Yin, Jiana Chen and Fangbo Cao \\ Crop and Environment Research Center, College of Agronomy, Hunan Agricultural University, Changsha, China
}

Coping with global warming by developing effective agricultural strategies is critical to global rice (Oryza sativa L.) production and food security. In 2020, we observed that the effect of heat stress on rice plants was mitigated by biochar application $\left(40 \mathrm{~g} \mathrm{~kg}^{-1}\right.$ soil) in a pot experiment with six consecutive days (6-11 days after transplanting) of daily mean temperatures beyond the critical high temperature $\left(33^{\circ} \mathrm{C}\right)$ for tillering in rice. To further determine the eco-physiological processes underlying the effect of biochar on resistance to heat stress in rice plants, we compared root-zone soil properties as well as some plant growth and physiological traits related to nitrogen (N) utilization between rice plants grown with and without biochar in the pot experiment. The results showed that the application of biochar improved the root-zone environment of rice plants by reducing soil bulk density, increasing soil organic matter content, and altering soil bacterial community structure by increasing the ratio of Proteobacteria to Acidobacteria, for example. As a consequence, root morphology, architecture, and physiological traits, such as $\mathrm{N}$ assimilation and transport proteins, as well as shoot $\mathrm{N}$ uptake and utilization (e.g., photosystems I and II proteins), were improved or up-modulated, while the heat-shock and related proteins in roots and leaves were down-modulated in rice plants grown with biochar compared to those without biochar. These results not only expand our understanding of the basic eco-physiological mechanisms controlling increased heat-stress tolerance in rice plants by the application of biochar, but also imply that improving the root-zone environment by optimizing management practices is an effective strategy to mitigate heat stress effects on rice production.

Keywords: biochar, heat stress, nitrogen utilization, rice, root zone

\section{INTRODUCTION}

Rice (Oryza sativa L.) feeds approximately $50 \%$ of the world's human population, and rice yield must increase by about $1 \%$ annually to meet the growing food demand that will result from population growth and economic development (Normile, 2008). However, this task is not easy to achieve due to changes in socioeconomic and physical environments related to rice production (Peng et al., 2009). Among these changes, global climate change is expected 
to be a particularly serious challenge for global rice production in the near future (Wassmann et al., 2009).

Global warming, the phenomenon of rising average air temperatures near earth's surface over the past 100-200 years, is a major aspect of climate change that threats rice production (Horie, 2019). Peng et al. (2004) reported that rice yield decreased by $10 \%$ when night temperatures during the growing season increased by $1^{\circ} \mathrm{C}$, which is associated with global warming. Moreover, global warming has and will continue to increase the frequency and severity of extreme weather events, such as droughts and heatwaves (Stott, 2016; Perkins-Kirkpatrick and Lewis, 2020), which can partially or completely damage crop production (Lesk et al., 2016). Therefore, it is crucial to find effective agricultural strategies to cope with global warming in order to ensure global food security (Wassmann et al., 2009; Horie, 2019).

In 2020, we conducted a pot experiment to determine the effect of biochar application on rice growth (Figure 1A; see the Materials and Methods section for details). Because the pots were placed on concrete-covered ground exposed to the sun, high temperatures were induced during the experimental period. Average daily maximum and minimum air temperatures around the rice plants reached 37.9 and $25.4^{\circ} \mathrm{C}$, respectively, during the period from transplanting to 18 days after transplanting (Figure 1B). Even more remarkably, there were six consecutive days (6-11 days after transplanting) with daily mean air temperatures (the average of daily maximum and minimum air temperatures) beyond the critical high air temperature $\left(33^{\circ} \mathrm{C}\right)$ for tillering in rice (Krishnan et al., 2011). In addition, high soil temperatures also occurred during the experimental period. For example, maximum and minimum soil temperatures were 42.1 and $27.6^{\circ} \mathrm{C}$, respectively, for the rice plants without biochar application (C0 treatment) and 43.0 and $27.5^{\circ} \mathrm{C}$ for the rice plants with biochar application ( $\mathrm{C} 1$ treatment) in the nine-day period after transplanting, when the maximum and minimum air temperatures around the rice plants were 42.9 and $26.6^{\circ} \mathrm{C}$, respectively (Figure $\mathbf{1 C}$ ).

In general, high temperature (or heat stress) can adversely affect the rice growth by disturbing photosynthetic activity and respiration rate (Fahad et al., 2019). However, unexpectedly and interestingly, the high temperatures seriously limited the growth of rice plants in the C0 treatment but seemed to not affect the growth of those in the $\mathrm{C} 1$ treatment in our pot experiment (Figure 1A). This observation indicates that the effect of heat stress on rice can be mitigated by applying biochar to regulate the root-zone environment.

It has been well documented that biochar application can improve soil properties and consequently promote root growth and nitrogen (N) utilization in rice (Huang et al., 2013, 2014, 2018; Xiang et al., 2017). In addition, the previous studies have shown that improving $\mathrm{N}$ availability can mitigate the negative effects of heat stress on several crops, such as rice, maize, and potato (Tawfik et al., 1996; Ordóñez et al., 2015; Liu et al., 2019). Heckathorn et al. (1996) found that $\mathrm{N}$ availability is closely related to patterns of accumulation of heat-shock proteins in plants, which are generally induced by

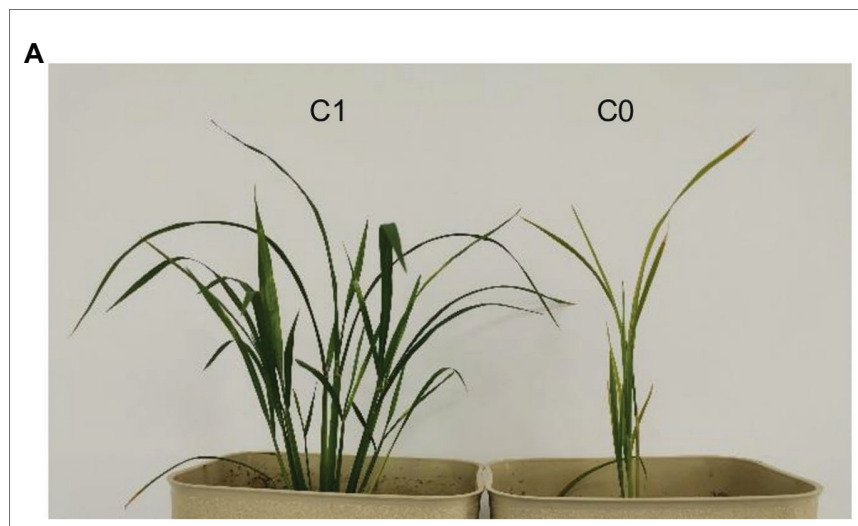

B

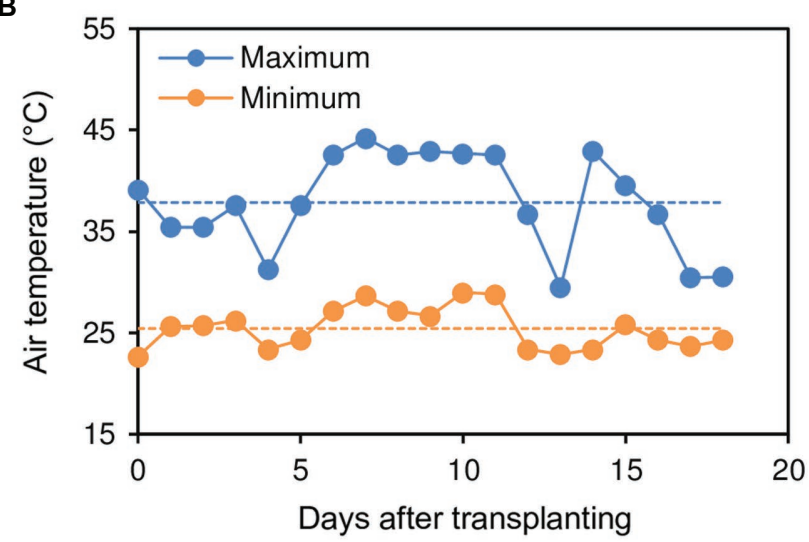

C

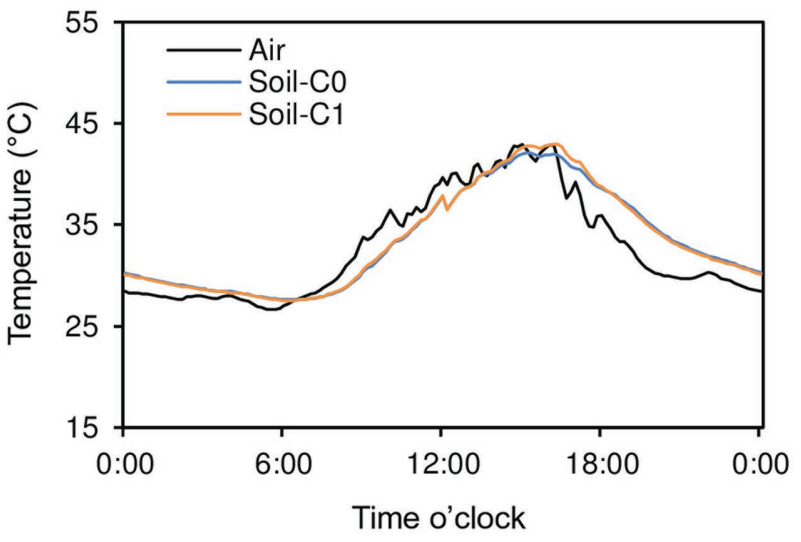

FIGURE 1 | (A) Rice plants grown in pots with (C1) and without (C0) biochar application shown at 18 days after transplanting, (B) daily maximum and minimum air temperatures around rice plants during the experimental period, and (C) air and soil temperatures for the $24 \mathrm{~h}$ on day 9 after transplanting.

heat stress and play an important role in the development of tolerance to heat stress (Parsell et al., 1993). Therefore, we hypothesized that the increased resistance to heat stress in rice plants in the $\mathrm{C} 1$ treatment compared to those in the C0 treatment is partly attributable to improved $\mathrm{N}$ utilization.

In this study, root-zone soil properties as well as some plant growth and physiological traits related to $\mathrm{N}$ utilization were compared between the $\mathrm{C} 0$ and $\mathrm{C} 1$ treatments. The objective of this study was to determine the eco-physiological processes 
underlying resistance to heat stress in rice by altering the root-zone environment by adding biochar to the soil.

\section{MATERIALS AND METHODS}

\section{Plants and Treatments}

The pot experiment was conducted at the Crop and Environment Center, Hunan Agricultural University, Changsha, China, in 2020. "Longliangyouhuazhan," a high-yielding hybrid rice variety, was grown in pots without $(\mathrm{C} 0)$ and with biochar application (C1). Each treatment consisted of six pots (replications). The pots were placed on concrete-covered ground exposed to the sun, causing high temperatures and heat stress for rice plants (see the Introduction section for details).

The soil used in the experiment was taken from the upper $20 \mathrm{~cm}$ layer of a rice field at the Experimental Farm of Hunan Agricultural University. The soil was a Fluvisol (FAO classification) with clay loam texture, $\mathrm{pH}=5.99$, organic matter $=22.7 \mathrm{~g} \mathrm{~kg}^{-1}$, total $N=1.32 \mathrm{~g} \mathrm{~kg}^{-1}$, and available $N=114 \mathrm{mg} \mathrm{kg}^{-1}$. The soil was air-dried, sieved, mixed, and then used to fill plastic pots (25-cm height, $20-\mathrm{cm}$ length, and $15-\mathrm{cm}$ width) with a weight of $5 \mathrm{~kg}$ pot $^{-1}$ and a depth of $\sim 20 \mathrm{~cm}$.

The tested biochar was a rapeseed straw biochar with specific surface area $=3.02 \mathrm{~m}^{2} \mathrm{~g}^{-1}$, average bore size $=2.14 \mathrm{~nm}$, $\mathrm{pH}=10.8$, total $C=440 \mathrm{~g} \mathrm{~kg}^{-1}$, and total $N=10.7 \mathrm{~g} \mathrm{~kg}^{-1}$. The application rate of the biochar was $200 \mathrm{~g} \mathrm{pot}^{-1}$ (or $40 \mathrm{~g} \mathrm{~kg}^{-1}$ soil) for the $\mathrm{C} 1$ treatment. This biochar application rate was selected according to a preliminary screening, which indicated that rice plants grown under a biochar rate of $40 \mathrm{~g} \mathrm{~kg}^{-1}$ soil performed better than those under a recommended rate (20 $\mathrm{g} \mathrm{kg}^{-1}$ soil) by Zhang et al. (2013). The biochar was applied 1 day before transplanting and was uniformly incorporated into the entire soil layer.

Pre-germinated seeds were sown in a seedling tray on 14 May. Twenty-day-old seedlings were transplanted into the pots with one hill per pot and one seedling per hill. Fertilizers used were urea for $\mathrm{N}$, single superphosphate for phosphorus $(\mathrm{P})$, and potassium chloride for potassium $(\mathrm{K})$ at doses of $0.35 \mathrm{~g} \mathrm{~N}$ pot $^{-1}, 0.10 \mathrm{~g} \mathrm{P}_{2} \mathrm{O}_{5}$ pot $^{-1}$, and $0.10 \mathrm{~g}$ $\mathrm{K}_{2} \mathrm{O}$ pot $^{-1}$, respectively. The $\mathrm{N}$ fertilizer was split-applied: $0.25 \mathrm{~g} \mathrm{~N}^{-1} 1$ day before transplanting and $0.10 \mathrm{~g} \mathrm{~N}$ $\operatorname{pot}^{-1} 7$ days after transplanting. The $\mathrm{P}$ and $\mathrm{K}$ fertilizers were both applied 1 day before transplanting. A water depth of $\sim 3 \mathrm{~cm}$ above the soil surface was maintained during the experimental period.

\section{Soil Sampling and Measurements}

Soils were sampled from three pots (replications) selected at random 18 days after transplanting to determine bulk density, organic matter content, available $\mathrm{N}$ content, and the bacterial community. All the soil samples were taken from the upper $10 \mathrm{~cm}$ layer where the rice roots were mainly distributed on the sampling day.

The bulk soil density was determined using the core method (Blake and Hartge, 1986). The organic matter content was measured by the potassium dichromate method (Walkley, 1947), and the available $\mathrm{N}$ content was assayed by the alkali-hydrolysis and diffusion method (Cornfield, 1960).

The bacterial community was investigated by analysis of the 16S rRNA gene sequence, which was performed by Novagene (Beijing, China). Quality-filtered and non-chimeric sequences were clustered to generate operational taxonomic units (OTUs) at a similarity level of 97\% using UPARSE, v7.0.1090 (Edgar, 2013). Taxonomic information for the OTUs was annotated against the GreenGene database (DeSantis et al., 2006) using the RDP classifier algorithm, v2.2 (Wang et al., 2007). Bacterial community diversity and richness indices, including observed species, and the Shannon, Simpson, Chao1, Good coverage, and abundance-based coverage estimators, and the phylogeny-based metrics ( $\mathrm{PD}$ whole tree) were calculated using QIIME, v1.9.1 (Caporaso et al., 2010). The relative abundance of each phylum was calculated by dividing the number of OTUs affiliated with a phylum by the total number of OTUs.

\section{Plant Sampling and Measurements}

On the day of soil sampling, roots and the uppermost fully expanded leaves were sampled from the three soil-sampled pots for proteomic analysis, and whole rice plants were sampled from the other three pots to measure root traits, including root length, diameter, surface area, and dry weight, and shoot traits, including tiller number per plant, leaf area per plant, specific leaf weight (SLW), leaf $\mathrm{N}$ content (LNC), shoot dry weight, and shoot $\mathrm{N}$ uptake.

The proteomic analysis was carried out by PTM BioLab Co., Ltd. (Hangzhou, China), using tandem mass tag (TMT) coupled to liquid chromatography-mass spectrometry/mass spectrometry (LC-MS/MS) in accordance with the following procedures:

\section{Protein Extraction}

The sample was ground into fine powder in liquid $\mathrm{N}_{2}$ and transferred to a $5 \mathrm{~mL}$ centrifuge tube. A four-fold volume of lysis buffer (including $10 \mathrm{~mm}$ dithiothreitol and $1 \%$ protease inhibitor cocktail) was added to each sample and then sonicated three times on ice using a high-intensity ultrasonic processor (Scientz, Ningbo, China). An equal volume of Tris-saturated phenol ( $\mathrm{pH}$ 8.0) was added, and then, the mixture was vortexed for $5 \mathrm{~min}$. After centrifugation $\left(4^{\circ} \mathrm{C}, 10 \mathrm{~min}, 5,500 \mathrm{~g}\right)$, the upper phenol phase was transferred to a clean centrifuge tube. Proteins were precipitated by adding five volumes of $0.1 \mathrm{M}$ ammonium acetate-saturated methanol and incubated at $-20^{\circ} \mathrm{C}$ overnight. After centrifugation at $4^{\circ} \mathrm{C}$ for $10 \mathrm{~min}$, the supernatant was discarded. The remaining precipitate was washed once with ice-cold methanol, followed by washing three times with ice-cold acetone. The protein was redissolved in $8 \mathrm{M}$ urea, and the protein concentration was determined with the bicinchoninic acid kit (Thermo Fisher Scientific, Rockford, IL, United States) according to the manufacturer's instructions. 
A

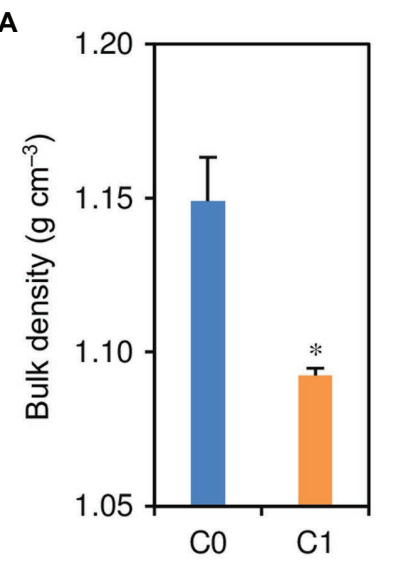

B

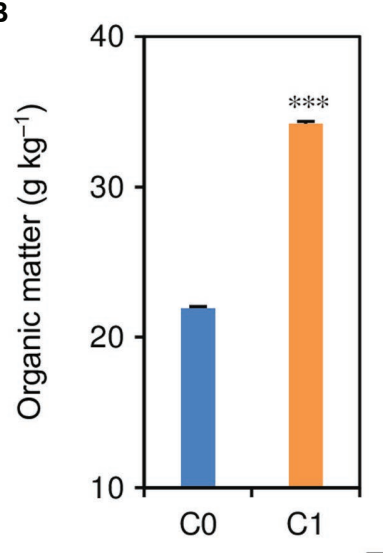

C

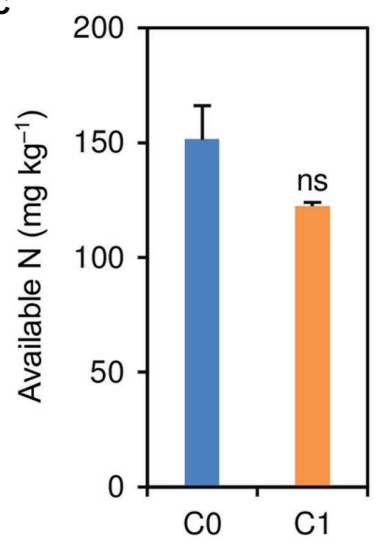

D

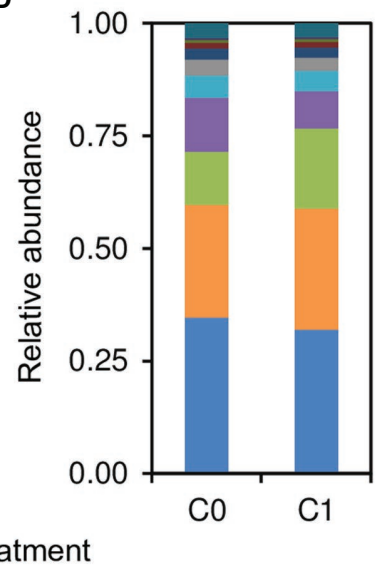

- Firmicutes

- Proteobacteria

- Bacteroidetes

- Acidobacteria

- Actinobacteria

- Chloroflexi

- Gemmatimonadetes

- Verrucomicrobia

- Cyanobacteria

- unidentified_Bacteria

- Others

FIGURE 2 | (A) Soil bulk density, (B) organic matter content, (C) available N content, and (D) relative abundance of bacterial phyla in treatments with (C1) and without (CO) biochar application. " and ${ }^{* * *}$ indicate that the means of the rice plants in $\mathrm{C} 1$ treatment are significantly different from those in the $\mathrm{C} 0$ treatment at the 0.05 and 0.001 levels, respectively. " $\mathrm{ns}$ " indicates that the mean of the rice plants in $\mathrm{C} 1$ treatment is not significantly different from that in the $\mathrm{C} 0$ treatment at the 0.05 level.

TABLE 1 | Soil bacterial community diversity and richness for rice plants grown with biochar application (C1) and those grown without biochar application (C0).

\begin{tabular}{lccc}
\hline Index & Co & C1 & Value of $\boldsymbol{p}$ \\
\hline Observed species & 2,824 & 2,770 & 0.247 \\
Shannon & 9.41 & 9.31 & 0.248 \\
Simpson & 0.995 & 0.995 & 1.000 \\
Chao1 & 2,970 & 3,012 & 0.508 \\
Good coverage & 0.994 & 0.992 & 0.703 \\
Abundance-based & 3,004 & 3,026 & 0.184 \\
coverage estimators (ACE) & & & \\
Phylogeny-based metrics & 199 & 204 & 0.195 \\
(PD whole tree) & & & \\
\hline
\end{tabular}

\section{Trypsin Digestion}

The protein solution was reduced with $5 \mathrm{~mm}$ dithiothreitol at $56^{\circ} \mathrm{C}$ for $30 \mathrm{~min}$ and alkylated with $11 \mathrm{~mm}$ iodoacetamide at room temperature in darkness for $15 \mathrm{~min}$. The protein sample was then diluted by adding $200 \mathrm{~mm}$ triethylammonium bicarbonate (TEAB) to insure the urea concentration $<2 \mathrm{M}$. Finally, trypsin was added at 1:50 trypsin-to-protein mass ratio for the first digestion overnight and at 1:100 trypsin-to-protein mass ratio for a second 4-h digestion.

\section{TMT Labeling}

After trypsin digestion, the peptide was desalted by Strata $\mathrm{X}$ C18 SPE column (Phenomenex, Torrance, CA, United States) and dried by vacuum centrifuging. Peptides were reconstituted in $0.5 \mathrm{M}$ TEAB and labeled by using TMT kit (Thermo Fisher Scientific, Rockford, IL, United States) according to the manufacturer's protocol. Briefly, one unit of TMT reagent was thawed and reconstituted in acetonitrile. The peptide mixtures were then incubated for $2 \mathrm{~h}$ at room temperature and pooled, desalted, and dried by vacuum centrifuging.

\section{High-Performance Liquid Chromatography Fractionation}

The tryptic peptides were fractionated into fractions by high $\mathrm{pH}$ reverse-phase high-performance liquid chromatography (HPLC) using Agilent 300 Extend C18 column (5 $\mu \mathrm{m}$ particle size, $4.6 \mathrm{~mm}$ internal diameter, and $250 \mathrm{~mm}$ length). Briefly, peptides were first separated with a gradient of $8-32 \%$ acetonitrile (pH 9.0) over 60 min into 60 fractions. Then, the peptides were combined into nine fractions and dried by vacuum centrifuging. 


\section{LC-MS/MS Analysis}

The tryptic peptides were dissolved in solvent A $(0.1 \%$ formic acid and 2\% acetonitrile), directly loaded onto a home-made reversed-phase analytical column $(15 \mathrm{~cm}$ length and $75 \mu \mathrm{m}$ internal diameter). The gradient was comprised of an increase from 7 to $26 \%$ solvent B ( $0.1 \%$ formic acid and $90 \%$ acetonitrile) over $26 \mathrm{~min}, 26-38 \%$ in $8 \mathrm{~min}$ and climbing to $80 \%$ in $3 \mathrm{~min}$ then holding at $80 \%$ for the last $3 \mathrm{~min}$, all at a constant flow rate of $500 \mathrm{nl} / \mathrm{min}$ on an EASY-nLC 1,000 ultra-performance liquid chromatography (UPLC) system (Thermo Fisher Scientific, Waltham, MA, United States). The peptides were subjected to a $\mathrm{N}$ solution index source followed by MS/MS in Q ExactiveTM Plus mass spectrometer (Thermo Fisher Scientific, Bremen, Germany) coupled online to the UPLC. The electrospray voltage applied was $2.2 \mathrm{kV}$. The $\mathrm{m} / \mathrm{z}$ scan range was $400-1,500$ for full scan, and intact peptides were detected in the Orbitrap at a resolution of 120,000 . Peptides were then selected for MS/MS using a normalized collision energy setting at 28 , and the fragments were detected in the Orbitrap at a resolution of 15,000 . Automatic gain control was set at 5E4. Fixed first mass was set as $100 \mathrm{~m} / \mathrm{z}$.

\section{Database Search}

The resulting MS/MS data were processed using Maxquant search engine (v.1.5.2.8). Tandem mass spectra were searched against UniProt $O$. sativa_indica database (37,383 sequences) concatenated with reverse decoy database. Trypsin/P was specified as cleavage enzyme allowing up to two missing cleavages. The mass tolerance for precursor ions was set at $10 \mathrm{ppm}$ in the first search and at $5 \mathrm{ppm}$ in the main search, and the mass tolerance for fragment ions was set at $0.02 \mathrm{Da}$. Carbamidomethylmodified cysteine residues were specified as a fixed modification, and oxidation of methionine was specified as a variable modification. The quantitative method is set to TMT-6plex. Both the false discovery rate for the identification of protein and propensity score matching were adjusted to $<1 \%$.

The root length, diameter, and surface area were determined using a WinRHIZO root analyzer system (Regent Instruments Inc., Quebec, Canada). Leaf area was measured with a LI-3000C leaf area meter (Li-Cor Inc., Lincoln, United States). The N content in the shoot (leaf and stem) was assayed using a Skalar SAN Plus segmented flow analyzer (Skalar Inc., Breda, Netherlands). The root and shoot (leaf and stem) dry weights were determined after oven-drying at $70^{\circ} \mathrm{C}$ to a constant weight. The SLW was calculated by dividing the leaf dry weight by the leaf area. The shoot $\mathrm{N}$ uptake was calculated by multiplying the shoot dry weight by the shoot $\mathrm{N}$ content.

\section{Data Analysis}

For statistical analysis of proteomics data, the log2-fold change of mean value of protein quantity in the $\mathrm{C} 1$ compared to the C0 treatment was calculated for each quantifiable protein and then subjected to two-tailed Fisher's exact test. The proteins with values of $p<0.05$ and fold changes $>1.3$ or $<1 / 1.3$ were considered to be differentially modulated. The differentially modulated proteins were annotated based on the Gene Ontology
(GO) and the Kyoto Encyclopedia of Genes and Genomes pathway databases. For analysis of other data, differences between the $\mathrm{C} 1$ and $\mathrm{C} 0$ treatments were evaluated by Student's $t$-test, with significance levels of $0.05,0.01$, and 0.001 .

\section{RESULTS}

\section{Root-Zone Soil Properties}

Biochar application significantly affected the soil bulk density and organic matter content but did not significantly affect soil available $\mathrm{N}$ content (Figures $\mathbf{2 A}-\mathbf{C}$ ). The $\mathrm{C} 1$ treatment had $5 \%$ lower soil bulk density but $56 \%$ higher soil organic matter content than did the $\mathrm{C} 0$ treatment.

Biochar application had no significant effects on soil bacterial diversity and richness (Table 1). However, the structure of the soil bacterial community was changed by the application of biochar (Figure 2D). Compared with the $\mathrm{C} 0$ treatment, the $\mathrm{C} 1$ treatment had $8-31 \%$ lower relative abundances of Firmicutes, Acidobacteria, Actinobacteria, Chloroflexi, and Gemmatimonadetes
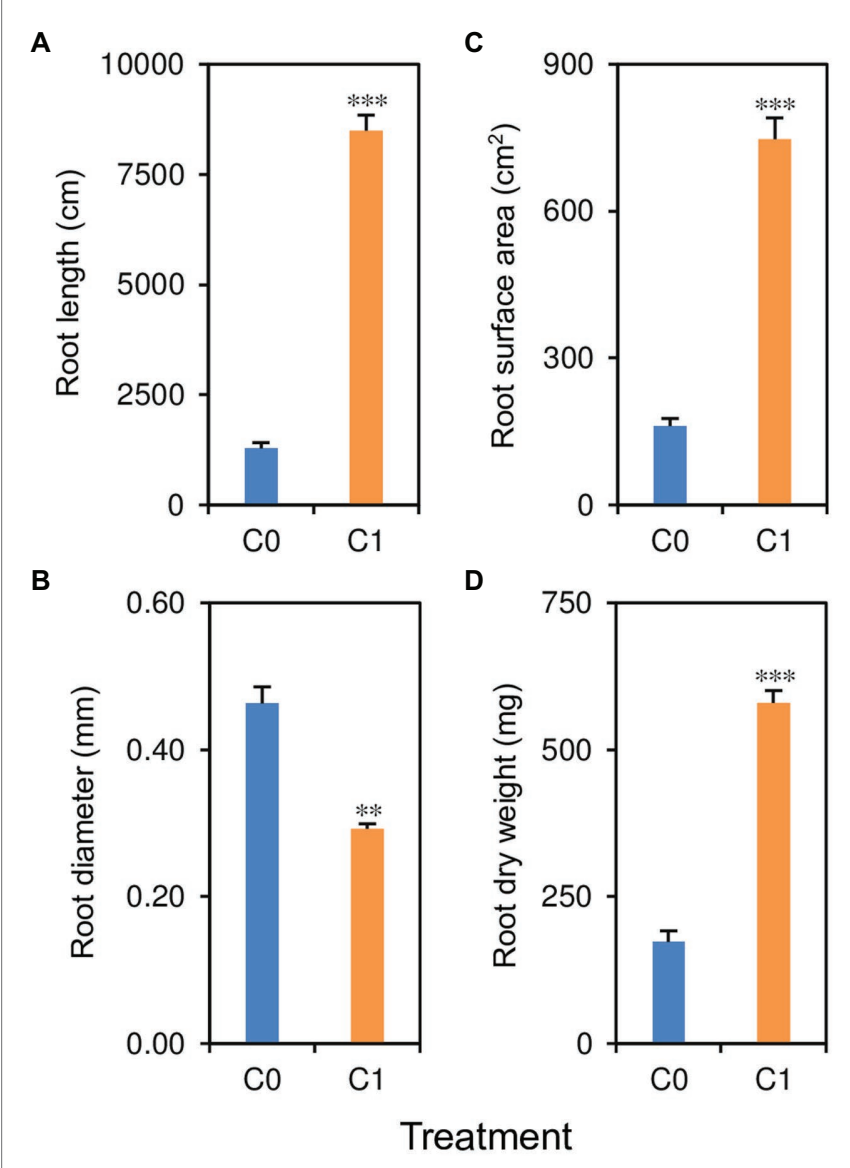

FIGURE 3 | (A) Root length, (B) root diameter, (C) root surface area, and (D) root dry weight in rice plants grown with $(\mathrm{C} 1)$ and without $(\mathrm{CO})$ biochar application. ${ }^{* *}$ and ${ }^{* * *}$ indicate that the means of the rice plants in $\mathrm{C} 1$ treatment are significantly different from those in the CO treatment at the 0.01 and 0.001 levels, respectively.

C

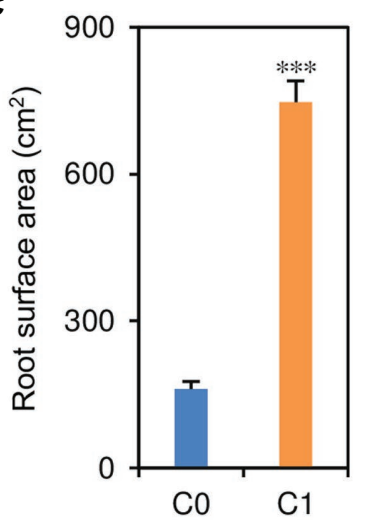

o.01


but $4-49 \%$ higher relative abundances of Proteobacteria, Bacteroidetes, Verrucomicrobia, and Cyanobacteria.

\section{Plant Growth Traits}

Biochar application had significant effects on root length, diameter, surface area, and dry weight (Figures 3A-D). Rice plants in the $\mathrm{C} 1$ treatment had $235-561 \%$ greater root length, surface area, and dry weight but $37 \%$ lower root diameter compared to those in the $\mathrm{C} 0$ treatment.

Shoot traits, including shoot $\mathrm{N}$ uptake, tiller number, leaf area, SLW, LNC, and shoot dry weight, were significantly affected by biochar application (Figures 4A-F). Compared with rice plants in the $\mathrm{C} 0$ treatment, rice plants in the $\mathrm{C} 1$ treatment had 51-396\% higher shoot $\mathrm{N}$ uptake, tiller number, leaf area, SLW, LNC, and shoot dry weight.

\section{Plant Physiological Traits}

Total number of proteins identified in roots and leaves were 6,670 and 5,326, respectively, of which 4,975 and 4,013, respectively, were quantifiable (data not shown). Biochar application significantly modulated proteins in both roots and leaves. A total of 835 and 2084 differentially modulated proteins were detected in roots and leaves of $\mathrm{C} 1$ compared to $\mathrm{C} 0$ rice plants, respectively (data not shown). In particular, 10 and 22 differentially modulated heat-shock or related proteins were identified in roots and leaves, respectively (Figure 5). All 10 of the identified differentially modulated heat-shock or related proteins in roots and 20 of the 22 identified differentially modulated heat-shock or related proteins in leaves were downmodulated in rice plants in the $\mathrm{C} 1$ treatment compared to those in the $\mathrm{C} 0$ treatment with fold changes of $0.234-0.769$.

In addition, we identified seven and three differentially modulated proteins in roots that are related to $\mathrm{N}$ metabolism and hormone activity, respectively (Figure 6). Five out of the seven differentially modulated proteins related to $\mathrm{N}$ metabolism were up-modulated with fold changes of 1.63-2.47, while the remaining two differentially modulated proteins related to $\mathrm{N}$ metabolism and all three differentially modulated proteins related to hormone activity were down-modulated with fold changes of $0.41-0.68$ in rice plants in the $\mathrm{C} 1$ treatment compared to those in the $\mathrm{C} 0$ treatment. The five up-modulated proteins related to $\mathrm{N}$ metabolism were glutamine synthetase (OsI_08842 and OsI_10575), glutamine amidotransferase type-2 domain-containing protein (OsI_03285), and two ammonium transporters (OsI_08109
A

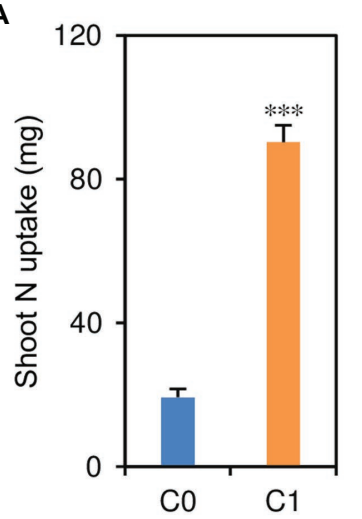

B

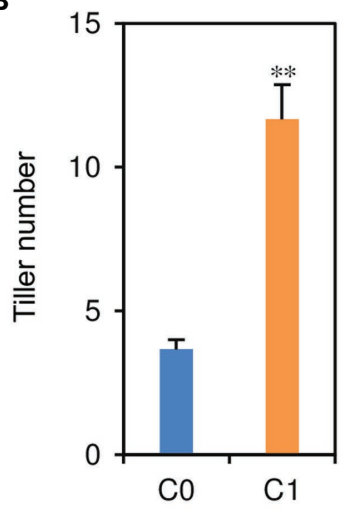

C

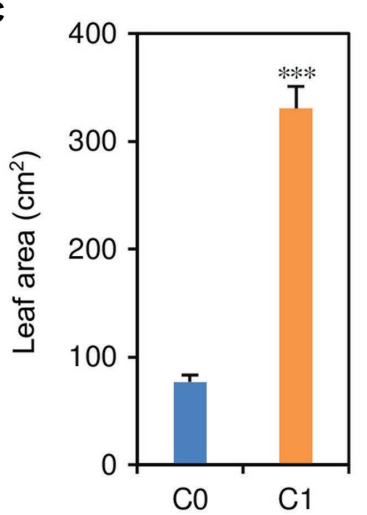

D

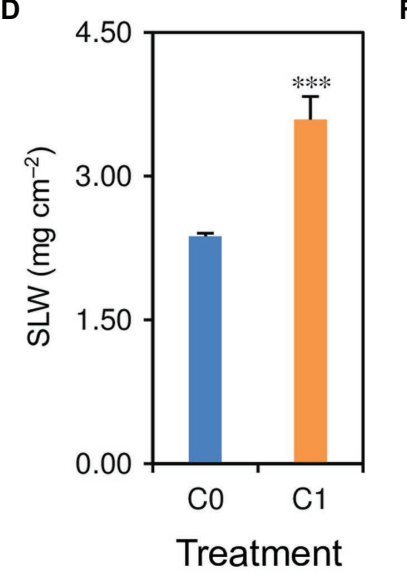

E

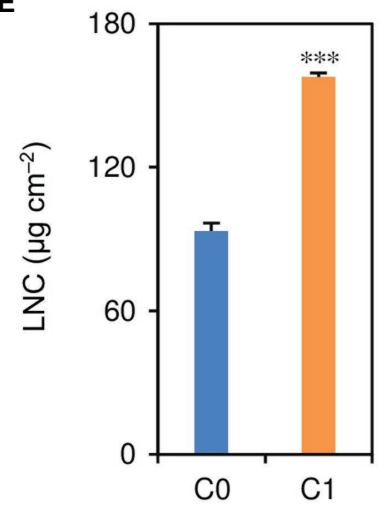

$\mathbf{F}$

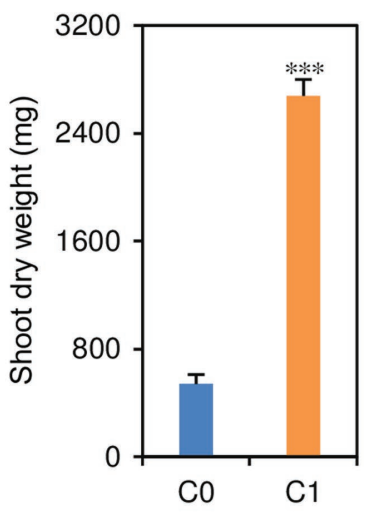

FIGURE 4 | (A) Shoot N uptake, (B) tiller number per plant, (C) leaf area per plant, (D) specific leaf weight, (E) leaf N content, and (F) shoot dry weight in rice plants grown with $(\mathrm{C} 1)$ and without $(\mathrm{CO})$ biochar application. ${ }^{* *}$ and ${ }^{* * *}$ indicate that the means of the rice plants in $\mathrm{C} 1$ treatment are significantly different from those in the CO treatment at the 0.01 and 0.001 levels, respectively. 


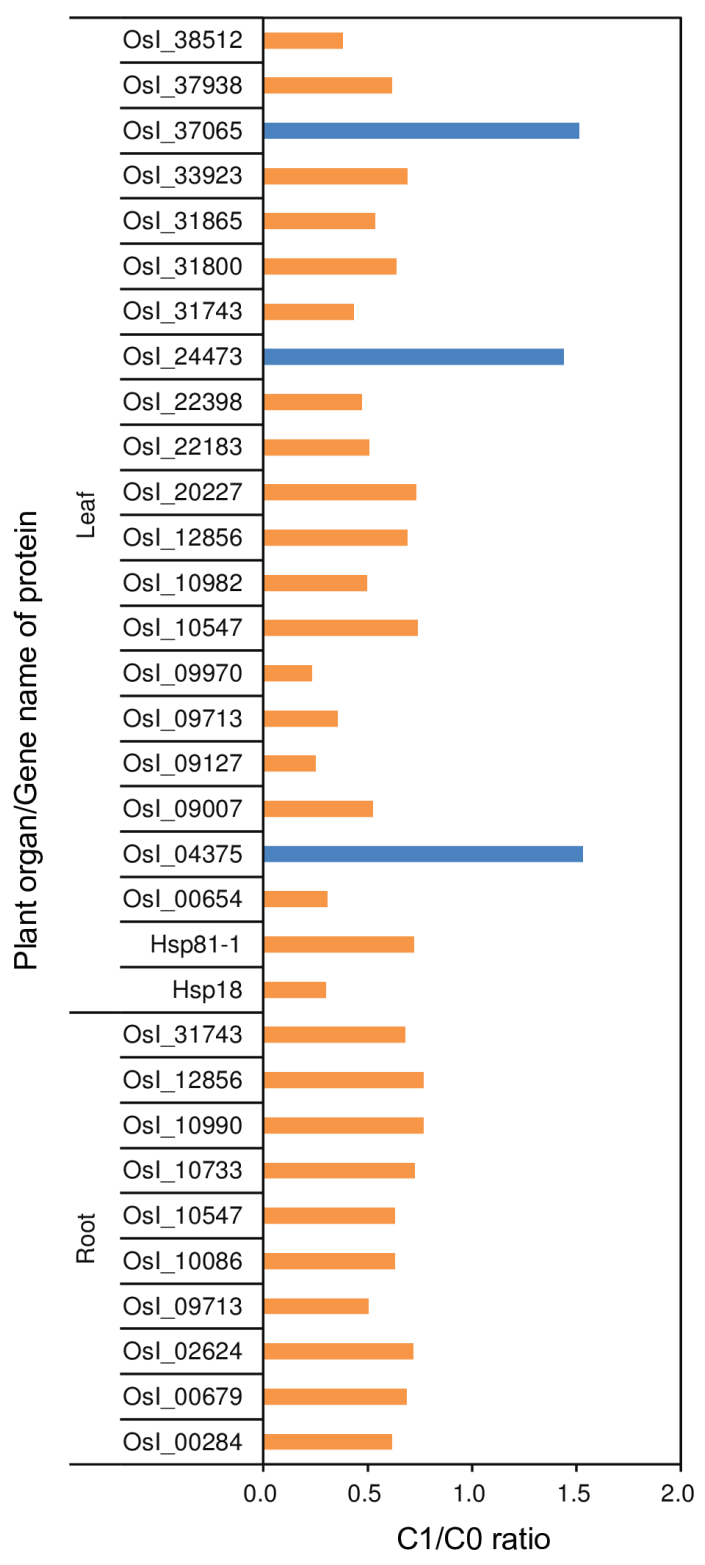

FIGURE 5 | Fold changes of differentially modulated heat-shock and related proteins in roots and leaves of the rice plants grown with biochar application (C1) compared to plants grown without biochar application (CO). Orange and blue bars represent the down- and up-modulated proteins in the $\mathrm{C} 1$ treatment compared to the $\mathrm{CO}$ treatment, respectively, respectively.

and OsI_16598), while the two down-modulated proteins related to $\mathrm{N}$ metabolism were both nitrate transporters (OsI_13072 and OsI_27853). The three down-modulated proteins related to hormone activity were abscisic stressripening protein 5 (ASR5), auxin efflux carrier component (OsI_23989), and ethylene-insensitive 2 (OsI_24945). We identified 49 differentially modulated proteins in leaves that are related to photosystems I and II, of which 44 differentially modulated proteins were up-modulated in rice plants in the $\mathrm{C} 1$ treatment compared to those in the $\mathrm{C} 0$ treatment with fold changes of 1.314-10.931 (Figure 7).

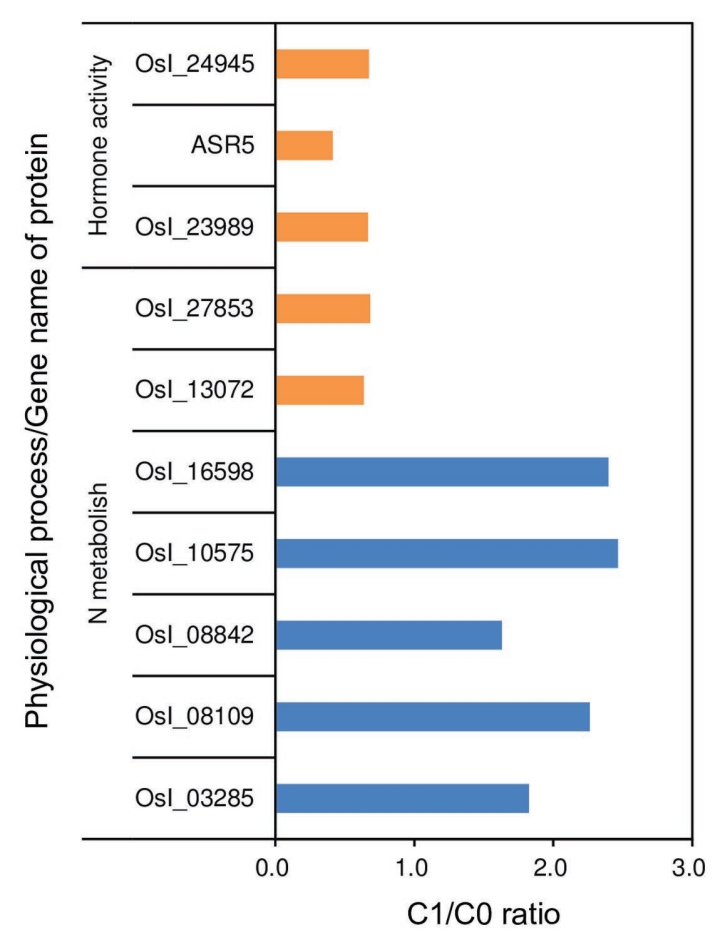

FIGURE 6 | Fold changes in differentially modulated proteins related to N metabolism and hormone activity in roots of rice plants grown with biochar application (C1) compared to plants grown without biochar application (CO). Orange and blue bars represent the down- and up-modulated proteins in the $\mathrm{C} 1$ treatment compared to the $\mathrm{C} 0$ treatment, respectively.

\section{DISCUSSION}

Heat-shock proteins are generally up-modulated in response to high temperatures (Parsell et al., 1993). In this study, the down-modulation of several heat-shock or related proteins in $\mathrm{C} 1$ compared to $\mathrm{C} 0$ rice plants under high temperature conditions indicates that the effect of heat stress was mitigated in the C1 treatment. This finding is consistent with the performance of plant growth traits and, again, demonstrates that the effect of heat stress on rice can be mitigated by regulating the rootzone environment through biochar application.

In the present study, we found that biochar application improved the root-zone soil physical and chemical properties, including reduced bulk density and increased organic matter content. It is well known that reduced soil bulk density can reduce resistance to root penetration and increase root development (Lijima et al., 1991). In this study, we found that root length, surface area, and dry weight were consistently higher in rice plants in the $\mathrm{C} 1$ treatment with lower soil bulk density compared to those in the $\mathrm{C} 0$ treatment. The improvements in root length, surface area, and dry weight in the $\mathrm{C} 1$ treatment might also be partially attributed to the increased organic matter content, which plays an important role in maintaining soil quality because it has a positive effect on a wide range of soil properties, such as reducing soil compaction (Soane, 1990). 


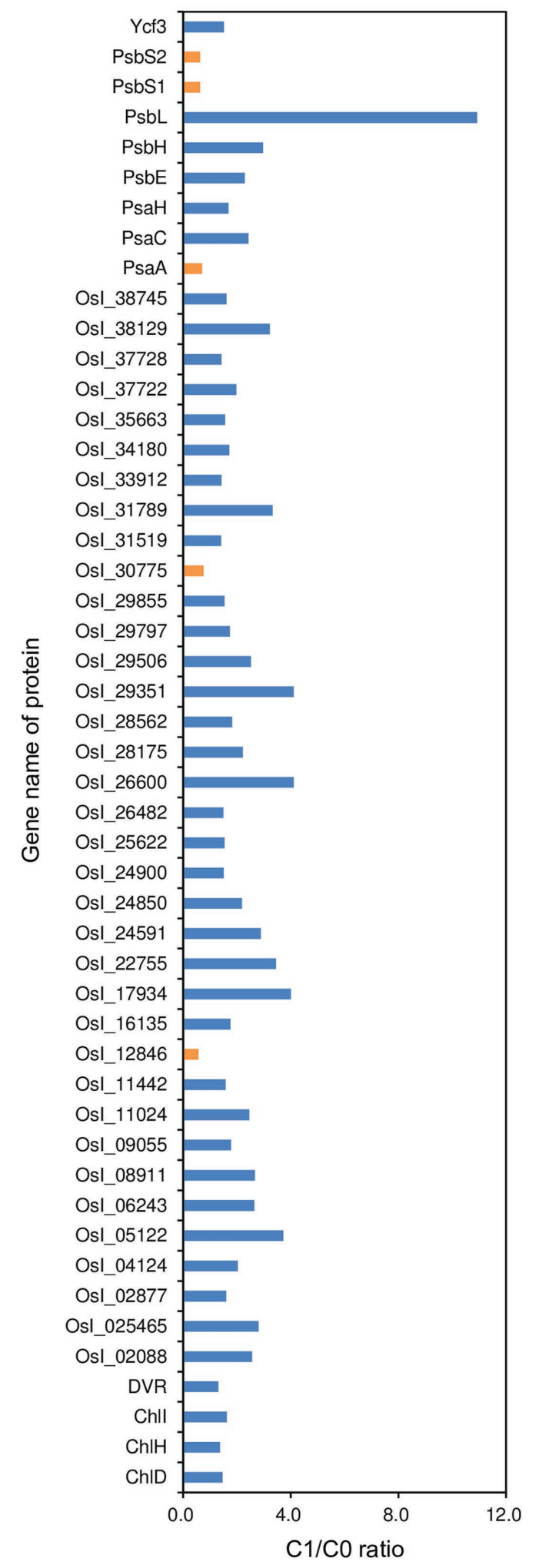

FIGURE 7 | Fold changes in differentially modulated proteins related to photosystems I and II in leaves of rice plants grown with biochar application (C1) compared to plants grown without biochar application (CO). Orange and blue bars represent the down- and up-modulated proteins in the $\mathrm{C} 1$ treatment compared to the $\mathrm{CO}$ treatment, respectively.
This study also showed that biochar application altered the structure of the soil bacterial community, which is directly tied to soil nutrient recycling (Jacoby et al., 2017). In this regard, it has been reported that the abundances of Proteobacteria and Acidobacteria are related to the nutrient status of soils, and high Proteobacteria/Acidobacteria ratios are indicative of copiotrophic soils (Smit et al., 2001; Babujia et al., 2016; Huang et al., 2020). This could be partially explained or supported by that the Proteobacteria is responsible for several biogeochemical functions in the soil, such as symbiotic $\mathrm{N}$ fixation and nutrient cycling remineralization, while the Acidobacteria has a propensity to thrive in oligotrophic conditions, typically coupled with lower plant productivity (Lewis et al., 2012). In this study, biochar application resulted in an increase in the relative abundance of Proteobacteria but a decrease in the relative abundance of Acidobacteria. This means that a higher Proteobacteria/ Acidobacteria ratio was induced by biochar application, suggesting that biochar application improved the soil nutrient status. This might also be partially responsible for the improvements in root length, surface area, and dry weight that resulted from biochar application.

In contrast to the effect of biochar application on increasing root length, surface area, and dry weight in rice plants, we found that root diameter was reduced in the biochar treatment $(\mathrm{C} 1)$. This was because biochar application facilitated the growth of many more lateral roots with smaller diameter in the rice plants (Figure 8). This observation indicates that biochar application improved root architecture because the lateral roots are critical to allowing the plants to take up water and minerals effectively (von Wangenheim et al., 2020). Auxin is required for lateral root formation. In the present study, biochar application led to a down-modulation of an auxin efflux carrier component (OsI_23989) in roots, leading to the accumulation of auxin in lateral root initials and promotion of lateral root growth (Kazan, 2013). Moreover, it has been documented that increasing endogenous abscisic acid and ethylene can inhibit lateral root formation in plants (Negi, 2008; Guo et al., 2009). In this study, ASR5 induced by abscisic acid (Jia et al., 2016) and ethylene-insensitive 2 (OsI_24945) involved in ethylene biosynthesis (Singh et al., 2015) were down-modulated in roots by biochar application. This indicates that reductions in abscisic acid and ethylene biosynthesis could also be responsible for the increased number of lateral roots in the biochar treatment.

Nitrate acts as a crucial signal in the regulation of lateral root development, and nitrate transporters have negative effects on lateral root development under low nitrate conditions (Sun et al., 2017). In this study, (1) the experiment was conducted under flooding conditions, where the soil nitrate should be low because nitrate replaces oxygen as the terminal electron acceptor in microbial respiration leading to denitrification and/or nitrate ammonification under flooding (Laanbroek, 1990); and (2) the application of biochar resulted in down-modulation of two nitrate transporters (OsI_13072 and OsI_27853). These results show that the increased number of lateral roots in the biochar treatment could also be related to the repression of nitrate transporters.

In addition to improve the morphological and architectural traits, biochar application up-modulated glutamine synthetase 


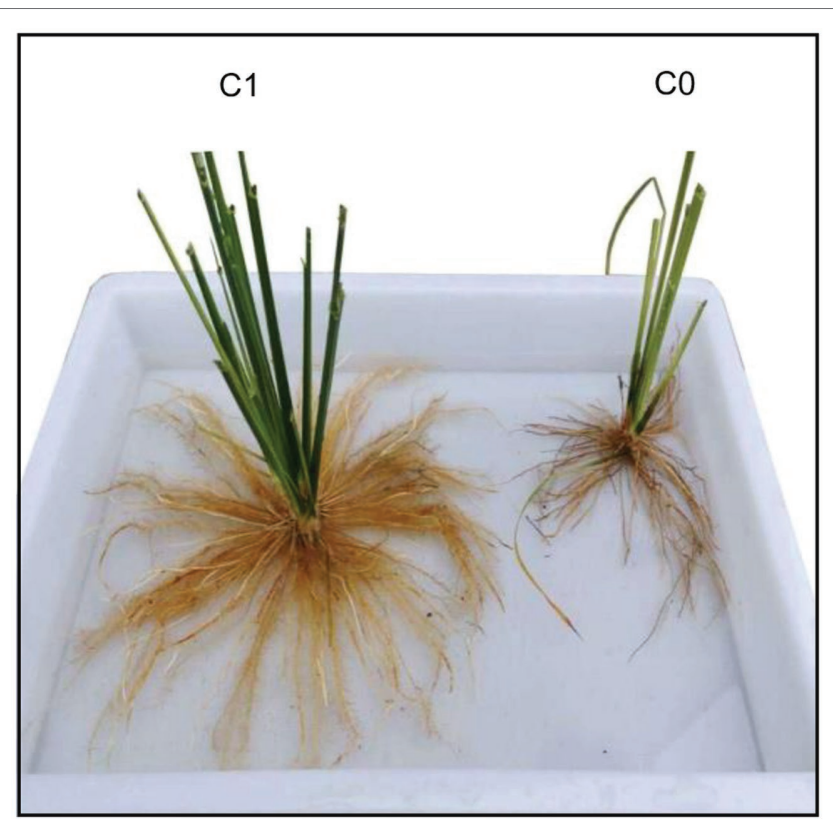

FIGURE 8 | Comparison on roots of rice plants grown with biochar application (C1) and without biochar application (CO).

(OsI_08842 and OsI_10575), glutamine amidotransferase type-2 domain-containing protein (OsI_03285), and two ammonium transporters (OsI_08109 and OsI_16598) in the root. As a consequence, shoot $\mathrm{N}$ uptake in rice plants was increased by biochar application. It is well known that $\mathrm{N}$ plays an important role in improving photosynthesis and growth in rice (Yin et al., 2017). Consistently, in this study, leaf area, SLW, LNC, most differentially modulated proteins related to photosystems I and II, tiller number, and shoot dry weight in rice plants were increased or up-modulated in parallel with increased $\mathrm{N}$ uptake due to biochar application. These improvements in shoot traits could be in turn responsible for the improved root morphological, architectural, and physiological traits resulting from biochar application, because root establishment and maintenance require assimilates produced by the shoot (Yang et al., 2012). Furthermore, the synchronous improvements in root and shoot traits could accelerate the transport of water in the soil-plant-atmosphere system, might resulting in transpiration cooling, and helping plants to avoid heat stress damage (Jagadish et al., 2015). However, additional studies are required to confirm this potential mechanism.

Taken together, the results of this study suggest that the application of biochar can improve soil physiological, chemical, and biological properties and consequently improve root morphological, architectural, and physiological traits as well as shoot $\mathrm{N}$ uptake and utilization, which ultimately mitigate the effect of heat stress on rice plants (Figure 9). This finding not only increases our understanding of the fundamental eco-physiological processes underlying increased heat-stress tolerance in rice plants that results from biochar application, but also implies that improving the root-zone environment by

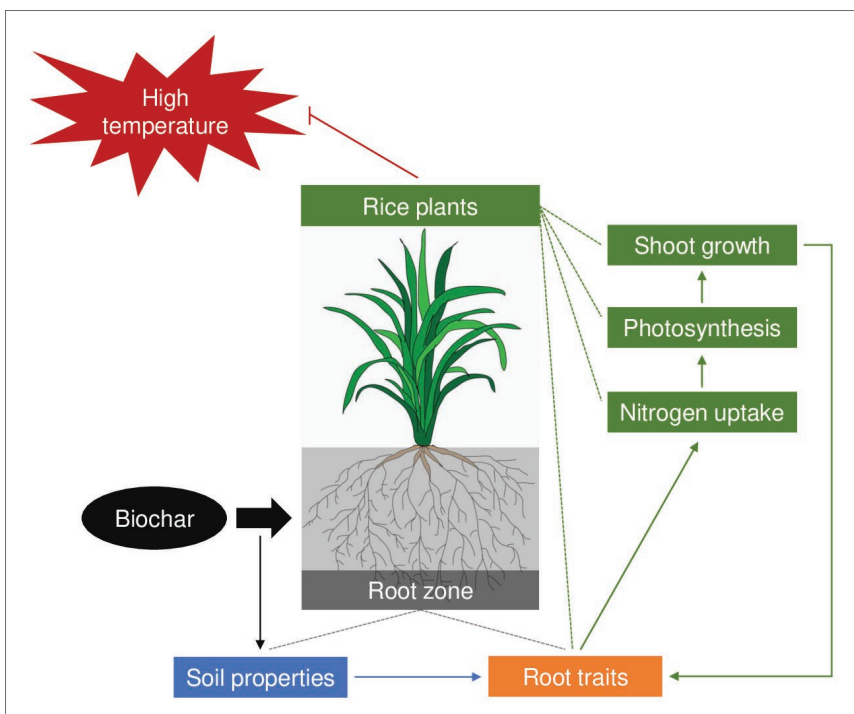

FIGURE 9 | A schematic diagram for the eco-physiological processes underlying the effects of biochar on resistance to heat stress in rice plants.

optimizing management practices is an effective strategy to mitigate heat stress in rice production. The finding of this study also highlights the need for further investigations to compare the effects of biochar application on the growth and eco-physiological characteristics in rice plants between normaland high-temperature conditions.

\section{DATA AVAILABILITY STATEMENT}

The original contributions presented in the study are publicly available. This data can be found at: https://figshare.com/articles/ dataset/MS_identified_information_xlsx/14945382/1.

\section{AUTHOR CONTRIBUTIONS}

$\mathrm{MH}$ conceived the experiment, analyzed the data, and wrote the manuscript. XY, JC, and FC performed the experiment. All authors have read and approved the final manuscript.

\section{FUNDING}

This research was supported by the Natural Science Foundation of Hunan Province of China (2019JJ50241), the Scientific Research Fund of Hunan Provincial Education Department of China (18C0158), and the National Natural Science Foundation of China (31460332).

\section{ACKNOWLEDGMENTS}

The authors thank other members of the Crop and Environment Research Center for their help with this research. 


\section{REFERENCES}

Babujia, L. C., Silva, A. P., Nakatani, A. S., Cantão, M. E., Vasconcelos, A. T. R., and Visentainer, J. V. (2016). Impact of long-term cropping of glyphosateresistant transgenic soybean [Glycine $\max$ (L.) Merr.] on soil microbiome. Transgenic Res. 25, 425-440. doi: 10.1007/s11248-016-9938-4

Blake, G. R., and Hartge, K. H. (1986). "Bulk density-core method," in Methods of Soil Analysis. ed. A. Klute (Madison, WI: American Society of Agronomy), 365-375.

Caporaso, J. G., Kuczynski, J., Stombaugh, J., Bittinger, K., Bushman, F. D., Costello, E. K., et al. (2010). QIIME allows analysis of high-throughput community sequencing data. Nat. Methods 7, 335-336. doi: 10.1038/nmeth.f.303

Cornfield, A. H. (1960). Ammonia released on treating soils with $\mathrm{N}$ sodium hydroxide as a possible means of predicting the nitrogen-supplying power of soils. Nature 187, 260-261. doi: 10.1038/187260a0

DeSantis, T. Z., Hugenholtz, P., Larsen, N., Rojas, M., Brodie, E. L., Keller, K., et al. (2006). Greengenes, a chimera-checked 16S rRNA gene database and workbench compatible with ARB. Appl. Environ. Microbiol. 72, 5069-5072. doi: 10.1128/AEM.03006-05

Edgar, R. C. (2013). UPARSE: highly accurate OTU sequences from microbial amplicon reads. Nat. Methods 10, 996-998. doi: 10.1038/nmeth.2604

Fahad, S., Adnan, M., Hassan, S., Saud, S., Hussain, S., Wu, C., et al. (2019). "Rice responses and tolerance to high temperature," in Advances in Rice Research for Abiotic Stress Tolerance. eds. M. Hasanuzzaman, M. Fujita, K. Nahar and K. Biswas (Cambridge: Woodhead Publishing), 201-224.

Guo, D., Liang, J., and Li, L. (2009). Abscisic acid (ABA) inhibition of lateral root formation involves endogenous ABA biosynthesis in Arachis hypogaea L. Plant Growth Regul. 58, 173-179. doi: 10.1007/s10725-009-9365-0

Heckathorn, S. A., Poeller, G. J., Coleman, J. S., and Hallberg, R. L. (1996). Nitrogen availability alters patterns of accumulation of heat stress-induced proteins in plants. Oecologia 105, 413-418. doi: 10.1007/BF00328745

Horie, T. (2019). Global warming and rice production in Asia: modeling, impact prediction and adaption. Proc. Jpn. Acad. Ser. B Phys. Biol. Sci. 95, 211-245. doi: $10.2183 /$ pjab.95.016

Huang, M., Fan, L., Chen, J., Jiang, L., and Zou, Y. (2018). Continuous applications of biochar to rice: effects on nitrogen uptake and utilization. Sci. Rep. 8:11461. doi: 10.1038/s41598-018-29877-7

Huang, M., Tian, A., Chen, J., Cao, F., Chen, Y., and Liu, L. (2020). Soil bacterial communities in three rice-based cropping systems differing in productivity. Sci. Rep. 10:9867. doi: 10.1038/s41598-020-66924-8

Huang, M., Yang, L., Qin, H., Jiang, L., and Zou, Y. (2013). Quantifying the effect of biochar amendment on soil quality and crop productivity in Chinese rice paddies. Field Crop Res. 154, 172-177. doi: 10.1016/j.fcr.2013.08.010

Huang, M., Yang, L., Qin, H., Jiang, L., and Zou, Y. (2014). Fertilizer nitrogen uptake by rice increased by biochar application. Biol. Fertil. Soils 50, 997-1000. doi: 10.1007/s00374-014-0908-9

Jacoby, R., Peulert, M., Succurro, A., Koprivova, A., and Kopriva, S. (2017). The role of soil microorganisms in plant mineral nutrition-current knowledge and future directions. Front. Plant Sci. 8:1617. doi: 10.3389/ fpls.2017.01617

Jagadish, S. V. K., Murty, M. V. R., and Quick, W. P. (2015). Rice responses to rising temperatures-challenges, perspectives and future directions. Plant Cell Environ. 38, 1686-1698. doi: 10.1111/pce.12430

Jia, H., Jiu, S., Zhang, C., Wang, C., Tariq, P., Liu, Z., et al. (2016). Abscisic acid and sucrose regulate tomato and strawberry fruit ripening through the abscisic acid-stress-ripening transcription factor. Plant Biotechnol. J. 14, 2045-2065. doi: 10.1111/pbi.12563

Kazan, K. (2013). Auxin and the integration of environmental signals into plant root development. Ann. Bot. 112, 1655-1665. doi: 10.1093/aob/mct229

Krishnan, P., Ramakrishnan, B., Reddy, K. J., and Reddy, V. R. (2011). Hightemperature effects on rice growth, yield, and grain quality. Adv. Agron. 111, 87-206. doi: 10.1016/B978-0-12-387689-8.00004-7

Laanbroek, H. J. (1990). Bacterial cycling of minerals that affect plant growth in waterlogged soils: a review. Aquat. Bot. 38, 109-125. doi: 10.1016/03043770(90)90101-P

Lesk, C., Rowhani, P., and Ramankutty, N. (2016). Influence of extreme weather disasters on global crop production. Nature 529, 84-87. doi: 10.1038/ nature 16467
Lewis, D. E., Chauhan, A., White, J. R., Overholt, W., Green, S. J., Jasrotia, P., et al. (2012). Microbial and geochemical assessment of bauxitic un-mined and post-mined chronosequence soils form Mocho Mountains, Jamaica. Microb. Ecol. 64, 738-749. doi: 10.1007/s00248-012-0020-3

Lijima, M., Kono, Y., Yamauchi, A., and Pardales, J. R. Jr. (1991). Effects of soil compaction on the development of rice and maize root systems. Environ. Exp. Bot. 31, 333-342. doi: 10.1016/0098-8472(91)90058-V

Liu, K., Deng, J., Lu, J., Wang, X., Lu, B., Tian, X., et al. (2019). High nitrogen levels alleviate yield loss of super hybrid rice caused by high temperatures during the flowering stage. Front. Plant Sci. 10:357. doi: 10.3389/fpls.2019. 00357

Negi, S., Ivanchenko, M. G., and Muday, G. K. (2008). Ethylene regulates lateral root formation and auxin transport in Arabidopsis thaliana. Plant J. 55, 175-187. doi: 10.1111/j.1365-313X.2008.03495.x

Normile, D. (2008). Reinventing rice to feed the world. Science 321, 330-333. doi: $10.1126 /$ science.321.5887.330

Ordóñez, R. A., Savin, R., Cossani, C. M., and Slafer, G. A. (2015). Yield response to heat stress as affected by nitrogen availability in maize. Field Crop Res. 183, 184-203. doi: 10.1016/j.fcr.2015.07.010

Parsell, D. A., Taulien, J., and Lindquist, S. (1993). The role of heat-shock proteins in thermotolerance. Philos. Trans. R. Soc. Lond. Ser. B Biol. Sci. 339, 279-285. doi: 10.1016/S1569-2558(08)60080-6

Peng, S., Huang, J., Sheehy, J. E., Laza, R. C., Visperas, R. M., Zhong, X., et al. (2004). Rice yields decline with higher night temperature from global warming. Proc. Natl. Acad. Sci. U. S. A. 101, 9971-9975. doi: 10.1073/ pnas.0403720101

Peng, S., Tang, Q., and Zou, Y. (2009). Current status and challenges of rice production in China. Plant Prod. Sci. 12, 3-8. doi: 10.1626/pps.12.3

Perkins-Kirkpatrick, S. E., and Lewis, S. C. (2020). Increasing trends in regional heatwaves. Nat. Commun. 11:3357. doi: 10.1038/s41467-020-16970-7

Singh, M., Gupta, A., and Laxmi, A. (2015). Ethylene acts as a negative regulator of glucose induced lateral root emergence in Arabidopsis. Plant Signal. Behav. 10:e1058460. doi: 10.1080/15592324.2015.1058460

Smit, E., Leeflang, P., Gommans, S., van den Broek, J., van Mil, S., and Wernars, K. (2001). Diversity and seasonal fluctuations of the dominant members of the bacterial soil community in a wheat field as determined by cultivation and molecular methods. Appl. Environ. Microbiol. 67, 2284-2291. doi: 10.1128/AEM.67.5.2284-2291.2001

Soane, B. D. (1990). The role of organic matter in soil compactibility: a review of some practical aspects. Soil Tillage Res. 16, 179-201. doi: 10.1016/01671987(90)90029-D

Stott, P. (2016). How climate change affects extreme weather events. Science 352, 1517-1518. doi: 10.1126/science.aaf7271

Sun, C., Yu, J., and Hu, D. (2017). Nitrate: a crucial signal during lateral roots development. Front. Plant Sci. 8:485. doi: 10.3389/fpls.2017.00485

Tawfik, A. A., Kleinhenz, M. D., and Palta, J. P. (1996). Application of calcium and nitrogen for mitigating heat stress effects on potatoes. Am. Potato J. 73, 261-273. doi: 10.1007/BF02849276

von Wangenheim, D., Banda, J., Schmitz, A., Boland, J., Bishopp, A., Maizel, A., et al. (2020). Early developmental plasticity of lateral roots in response to asymmetric water availability. Nat. Plants 6, 73-77. doi: 10.1038/ s41477-019-0580-z

Walkley, A. (1947). A critical examination of a rapid method for determining organic carbon in soils: effect of variations in digestion conditions and inorganic soil constituents. Soil Sci. 63, 251-264. doi: 10.1097/00010694194704000-00001

Wang, Q., Garrity, G. M., Tiedje, J. M., and Cole, J. R. (2007). Naïve Bayesian classifier for rapid assignment of rRNA sequences into the new bacterial taxonomy. Appl. Environ. Microbiol. 73, 5261-5267. doi: 10.1128/AEM. 00062-07

Wassmann, R., Jagadish, S. V. K., Heuer, S., Ismail, A., Redona, E., Serraj, R., et al. (2009). Climatic change affecting rice production: the physiological and agronomic basis for possible adaptation strategies. Adv. Agron. 101, 59-122. doi: 10.1016/S0065-2113(08)00802-X

Xiang, Y., Deng, Q., Duan, H., and Guo, Y. (2017). Effects of biochar application on root traits: a meta-analysis. Glob. Change Biol. Bioenergy 9, 1563-1572. doi: 10.1111/gcbb.12449 
Yang, J., Zhang, H., and Zhang, J. (2012). Root morphology and physiology in relation to the yield formation of rice. J. Integr. Agric. 11, 920-926. doi: 10.1016/S2095-3119(12)60082-3

Yin, X., Huang, M., and Zou, Y. (2017). Nitrogen deficiency effects on growth and photosynthesis in no-till direct seeded super hybrid rice. Crop. Res. 52, 116-120. doi: 10.5958/2454-1761.2017.00002.X

Zhang, W., Meng, J., Wang, J., Fan, S., and Chen, W. (2013). Effect of biochar on root morphological and physiological characteristics and yield in rice. Acta Agron. Sin. 39, 1445-1451. doi: 10.3724/SP.J.1006.2013.01445

Conflict of Interest: The authors declare that the research was conducted in the absence of any commercial or financial relationships that could be construed as a potential conflict of interest.
Publisher's Note: All claims expressed in this article are solely those of the authors and do not necessarily represent those of their affiliated organizations, or those of the publisher, the editors and the reviewers. Any product that may be evaluated in this article, or claim that may be made by its manufacturer, is not guaranteed or endorsed by the publisher.

Copyright (c) 2021 Huang, Yin, Chen and Cao. This is an open-access article distributed under the terms of the Creative Commons Attribution License (CC BY). The use, distribution or reproduction in other forums is permitted, provided the original author(s) and the copyright owner(s) are credited and that the original publication in this journal is cited, in accordance with accepted academic practice. No use, distribution or reproduction is permitted which does not comply with these terms. 